\title{
Evaluation the effect of Silybum marianum ointment on episiotomy wound healing and pain intensity in primiparous women: a randomized triple blind clinical trial
}

\author{
Elmira Toomari ${ }^{1,2}$, Sepideh Hajian ${ }^{2,3^{*}}$, Faraz Mojab ${ }^{4}$, Tayebe Omidkhah ${ }^{5}$ and Malihe Nasiri ${ }^{2,6}$
}

\begin{abstract}
Background: Episiotomy is the most commonn surgical procedure in midwifery which as any other wounds can cause infection or delay in healing.

The current study aimed to determine effect of Silybum marianum ointment on pain severity and healing of episiotomy wound in primiparous women referring to Shahid Nourani Hospital at 2019.

Methods: This research was done as a randomized, triple-blind clinical trial on 87 priiparous women (44 indivdiuals in Silybum marianum ointment group and 43 indivdiuals in placebo group) referred to Shahid Nourani Hospital in Talesh (Guilan Province), Iran at September 2019.

After labor and performing episiotomy, twice a day for 10 days as a fingertip size of the ointment was prescribed to be topically used on the episiotomy incision for both groups (Silybum marianum ointment or placebo ointment).

Data gathering was done using demographic and midwifery information questionnaire, Episiotomy healing assessment: Redness, Edema, Ecchymosis, Discharge, Approximation)REEDA Scale (REEDA Scale: Redness(R); Edema (E), Ecchymosis(E), Discharge from the wound(D); Approximation of the perineal tissues(A))(scale, and visual analogue scale of pain. Examination of healing status of the perinea incision was performed during first $12 \mathrm{~h}$, fifth day and tenth day after labor.Kolmogrov-Smirnov test was used in order to investiagte nomrality of data distribution of quantitative data, and two- independent samples t test, Chi square, repeated measures two factorial analysis of variance and Fischer's exact test were used. SPSS software version 23 was used to analyze data and 0.05 was considered as signifcance level.
\end{abstract}

Results: Both groups of Silybum marianum and placebo groups did not differ regarding demographic and midwifery characteristics, hygiene status prior to intervention $(P>0.05)$.

Mean difference of pain severity and REEDA scale in Silybum marianum ointment group in $12 \mathrm{~h}$ after labor, at fifth day and tenth day after labor was significant comparing to control group which indicates decline in episiotomy pain severity and faster wound healing $(P<0.001)$.

*Correspondence: s.hajian@sbmu.ac.ir; hajian74@yahoo.com

${ }^{3}$ Midwifery \& Reproductive Health Research Center, School of Nursing \&

Midwifery, Shahid Beheshti University of Medical Sciences, Tehran, Iran

Full list of author information is available at the end of the article

(c) The Author(s) 2021. Open Access This article is licensed under a Creative Commons Attribution 4.0 International License, which permits use, sharing, adaptation, distribution and reproduction in any medium or format, as long as you give appropriate credit to the original author(s) and the source, provide a link to the Creative Commons licence, and indicate if changes were made. The images or other third party material in this article are included in the article's Creative Commons licence, unless indicated otherwise in a credit line to the material. If material is not included in the article's Creative Commons licence and your intended use is not permitted by statutory regulation or exceeds the permitted use, you will need to obtain permission directly from the copyright holder. To view a copy of this licence, visit http://creativecommons.org/licenses/by/4.0/. The Creative Commons Public Domain Dedication waiver (http://creativeco mmons.org/publicdomain/zero/1.0/) applies to the data made available in this article, unless otherwise stated in a credit line to the data. 
Conclusions: Silybum marianum ointment ointment accelerates episiotomy wound healing rate due to its healing properties and decreases pain severity.

Trial registration: This study was registered in Iranian Registry of Clinical Trials in 10/08/2019 with the IRCT ID: IRCT201811100411603N1.

Keywords: Episiotomy, Pain, Wound healing, Silybum marianum

\section{Background}

Episiotomy means pudendal incision. Perineotomy refers to perinea incision. This incision is made at the second phase of labor in order to increase size of soft tissue space of the pelvic outlet, prevent ruptures, facilitate labor, and decrease fetus labor time and is done as two forms of medial and lateral incision [1].

Recommendation on undergoing episiotomy is indicated in the conditions including: breech presentation, labor by forceps or vacuum, permanent occiput posterior, and cases in which not performing episiotomy might cause perinea rupture and need to premature labor due to worry on fetal heart pulse $[1,2]$.

There is considerable increase in episiotomy worldwide [3]. More than $85 \%$ of the labors in Vietnam are done through vaginal method which amongst them, $100 \%$ of primiparous women underwent episiotomy [4]. In addition, prevalence of episiotomy is reported as $47.8 \%$ [5] in Erbil, Iraq, 56.3\% in Turkey [6], 63.1\% in Enugu, western south of Nigeria [7], 8\% in Netherlands, 20\% in England, 28\% in Argentina, $40.6 \%$ in Austria, 50\% in United States, and 54\% in Northern America [8].

There is no comprehensive report on performing this surgical incision in Iran, but in most hospitals of the country, it is considered as common method specifically for birth of neonates of primiparous women [9]. However, as any other incisions, some complications are reported for this procedure including bleeding, increase of incision toward anal sphincter, perinea pain, dyspareunia, infection, perinea hematoma, and formation of recto-vaginal fistula [2], and due to involvement of pelvic muscles, it can interfere with many usual activities such as sitting, walking, standing, huddling, urination, and defecation, and disturb the mother who already delivered [10]. Results of the studies showed that perinea damage does not only cause physical damage but also induce emotional and mental damages [11].

Numerous factors are effective in healing of wounds, such as, upon local wound factors, systemic mediators, the injury type [12], infection, hypotension, age, nutritional status, systemic diseases, exposing to radiation, estrogen level, medication use, mental and psychological status, age, wound type [13], smoking, pulmonary diseases and peripheral vascular disease (PVD) result in hypoxia [14], wound leading cause, Ideal Dressing [15], duration of diagnosis of the wound until surgery, factors related to efficacy of treatment of wound surgeries [16].

Episiotomy incision is healed during 3 weeks after labor naturally and without any confounding factors such as infection [1]. Phases of wound healing include as, hemostasis/inflammation, proliferation, and remodeling [17]. However, edema, redness, bruising are reported in 26.2, $6.6,3.3 \%$ of women, respectively who underwent episiotomy in first $24 \mathrm{~h}$ after labor [18]. Perinea pain severity can go on in first day beyond $90 \%$ and in $88 \%$ of cases; this pain is continued over 2 months after labor [19].

Numerous attempts can be done after labor following episiotomy to reduce perinea pain and accelerate wound healing, which are applicable through two methods of pharmaceutical and non-pharmaceutical methods (cryotherapy [20], laser therapy [21], pelvic floor muscle trainings [22], acupuncture [23], and perinea massage [24], and electrical stimulating [25]). There is increasing tendency in the world specifically in Iran in recent years to investigate the physiologic and pharmacologic effects of these herbal compounds and using them which the most important reasons of the tendency to these approaches include: lesser side effects, variety of the effective compounds in the herbs, lower specific costs comparing to chemical pharmaceutical elements, development of industries depended to culturing medicinal herbs, prevention from currency outflow from the country, producing useful job [26]. Despite having a few evidence of the above mentioned herbal agents efficacy on episiotomy recovery, there are no formal recommendations for wound healing after episiotomy in Iran including use of herbal products and medical advice for episiotomy care are summarized in adherence to personal hygiene and patient self-care basics such as using regular warm bath and pain killers but herbal remedies are not recommended by physicians routinely owing to the lack of national recommendations in this field.

Amongst medicinal herbs compounds such Hypericum perforatum cream [27], chamomile cream [11], Aloe Vera Ointment [28], Ananas comosus [29], Curcuma Longa Ointment [30], Aloe vera and Calendula persica Ointment [31], one of the herbal compounds recommended for its properties including wound healing in the studies is Silybum marianum (S. marianum) [32]. S. marianum is a plant belonged to family Asteraceae which is also 
named as Khar Maryam, Maritighal, in Persian languages [33]. This annual and biennal plant grows to a height of $1.5 \mathrm{~m}$ and is wildflower [34]. Silybum marianum grows in European, Asian, and American countries. Disturbtion of this plant in Iran, is in areas of Gonbad Kavoos, Gorgan, Kelardasht, Mughan desert, Posht kooh, Ahvaz, Shoush and Kazerun [35].

The most important reasons which can be pointed in order to use this herb are the properties of anti-inflammatory, stimulating collagen synthesis, angiogenesis, vasodilatation, decline in bleeding and edema of the wound which are done in microscopic studies [8].

$S$. marianum contains numerous compounds including: sallying $\mathrm{A}$ and $\mathrm{B}$, silydianin, silychristin, Apigenin, dehydrosilyn, deoxysilychristin and deoxydianin. S. marianum is confirmed to be effective in treatment of hepatic, renal, dermatological diseases, blood sugar control and lipid metabolism, immune system boosting and anti-carcinogen [36].

Silybin is the main component of silymarin effective in synthesis of collagen type 1 [37]. Silymarin improves wound healing process by increase in stromelysine 1 gene expression and extracellular matrix components including glycosaminoglycans and collagen content [38] and has strong antioxidant power which helps prevention of oxidative damage and progression of treatment process, therefore, effect of silymarin on wound healing process can be attributed to the effect of epithelialization and inflammation reduction [39] due to its antioxidant and anti-inflammatory properties [40].

It has been showed that silymarin ointment is a promise therapeutic agent for wound healing in rats for such properties [41]. In addition, findings of a study on the patients with second-degree fire burns indicated that at least 1 month use of oral silymarin lead to faster injury recovery compared to the placebo [42].

Owing to the antioxidant, antimicrobial, antifungal, anti-inflammatory, and analgesic properties of $S$. marianum in a few studies $[8,43,44]$, and due to that there is no research to date through randomized controlled design in order to assess the topical Silybum marianum seed ethanol extract on wound healing in human, and since there is a need to use of effective, low risk, accessible and low-cost methods for postpartum women, the current study aimed to determine effect of Silybum marianum ointment on wound healing and pain severity of episiotomy in primiparous women.

\section{Methods}

\section{Study design and participants}

This is a randomized, triple-blind clinical trial performed to assess effect of Silybum marianum ointment on wound healing and pain severity of episiotomy in primiparous women in 2019. This trial adhered to CONSORT guidelines and included CONSORT checklist as a supplementary file 1.

Sample size was estimated using the article by Taleb et al. [45] and by considering $90 \%$ test power and the observed effect size of 0.70 in each group at 42 individuals which was increase to at least 45 individuals in each group by considering attrition rate).)

Incusion criteria were as follow: low risk pregnancy, being primiparous, age range of $18-35$ years old. BMI of 18.5-29.9, resident in Talesh, ability of reading and writing, singleton birth with cephalic presentation. Vaginal labor with media-lateral episiotomy, without rupture andwithout strumental delivery, no rupture in corioamnion membrane longer than $24 \mathrm{~h}$, normal and spontaneous placental abruption up to $30 \mathrm{~min}$ after neonate abortion, no perineal swelling immediately after episiotomy, lack of history of topical and herbal medications allergy, lack of history of previous damage or surgery or visible lesions in perinea.

Exclusion crietria inlcudes: lack of referral of mother to hospital in fifth an tenth day after labor, lack of tendency to continue partcipating in the study, not using ointment regularly and based on instructions, not using washing serum for washing sutures location regularly and based on the instructions (lesser than twice a day), initiation of sexual intercourse during 10 days after labor, occurrence of allergy or complications related to the medication (which in case of incidence of allergy, the particpant was excluded from the study and reported).

\section{The study tools}

Instruments include: 1-The participants' characteristics and midwifery information questionnaire, 2-the antibiotic use record checklist, 3- side effects of the medication and health status sheet, 4- perinea improvement assessment checklist, 5- visual analogue scale.

Side effects of the medication include allergy, infection, itching, burning, stinging, dryness in the region of wound, fever and ague and health status sheet including six questions on health issues to assess adherence to perinea health by each participant which was used in two studies previously $[27,46]$ and was made by the researcher. Score of 0-1 was allocated to each question. Then, based on the scores obtained, health status of the samples was classified in three levels of poor (0 to 2), medium (3 to 4 ) and good (5 to 6 ).

Perinea recovery assessemnt checklist: disposable paper ruler was used in order to assess perinea recovery and the assessment was done in lithotomy status and through using examination light by the REEDA scale. This tool conisists of five variables or criteria which investigates oedema, bruising, erythema, wound secretions, 
and wound edges adherence after episiotomy, which this tool is used to assess recovery of perinea wound in previous studies $[47,48]$. A score of $0-3$ is allocated to each variable in the scale. Score of each variable is computed seperately, sum of the scores are $0-15$, and the closer score to 15 indicates greater traums [49].

Visual analogue scare of pain: this tool was used in order to measure pain severity which is as a $10-\mathrm{cm}$ ruler with 11 numbers. The ruler is numerized from 0 to 10 , in which zero shows no pain, 1-3 shows mild pain, 4-7 shows moedrate pain, and $8-10$ shows severe pain.

In order to determine reliabiity of the health status assessment sheet, test -retest method was used on ten primiparous women before sampling the reasearch subjects within 2 weeks. Reliability and validity of the perinea recovery assessment form was confirmed in a few studies [50,51].

Inter rater agreement method was used to reassure the consensus between two examiners (researcher and her colleague who are at the same level regarding job experience and scientific level), as ten samples were selected and their wound healing scores were assessed separately. Then correlation coefficient of the assessment scores between two examiners was computed.

Reliability of the disposable ruler was assessed with a non-stretch tape (Laica, Italy) with accurateness of $1 \mathrm{~mm}$.

Reliability and validity of the visual sclae of pain was confirmed in various studies [52-54].

\section{Study material}

S. marianum seeds (Asteraceae) were bought from herbal market in Tehran on September 2019. After confirm the seeds (in Medicinal Plant Lab., School of Pharmacy), they were powdered and extracted through soaking in ethanol (maceration X 4), the extracts were mixed together and were concentrated in fewer of $40^{\circ} \mathrm{C}$, According to the similar studies $[27,55]$ the ointment with concentration of $3 \%$ was prepared from this extract with a eucerin basis, and the $30 \mathrm{~g}$ tubes were filled. Placebo was prepared with eucerin and in the similar tubes and was named with the codes of A and B, respectively. Both ointments were autoclaved. Total flavonolignans (as silybin) using ultraviolet spectrophotometry was determined at $1.53 \%$.

In order to blind samples and researchers on the type of medication used in two study groups, intervention and control groups (gold standard group), the ointments were made the same in color, odor, and medication shape.

\section{Study implementation}

Sampling was done through purposive sampling method and based on includion criteria. After explaining of the study objectives to the all participants and obtaining their written consent, they entered the study and assigned into the intervention and control groups (gold standard group) through random allocation method using Excel software, version 2019. First, in a column, groups A, B and below were imported; Because the number of samples in each group was determined, therefore, 45, B, A would enter into the following row. In the other column, Using the command RAND, the random numbers were generated. In the next step, using the Sort order, random numbers generated from small to large or reversed, which caused the order of the groups, A and B, to change. Using the new order, people are assigned to different groups. After that, the software determines how to allocate people based on random numbers. For example, in random allocation, the first person may be allocated to the placebo, the third person would be in the intervention group, and so on.

During the hospitalization in labor, in case of emergency condition of a participant such as cesarean section, she was excluded from the study and another eligible participant was replaced until the samples size was completed.

In order to decrease assessment bias and increase of accuracy of the data, the researcher, partcipants and statistician were not awared of the used medication. The participants' characteristics and midwifery information forms were completed by the first author at the beginning of the labor admission and other necessary data were recorded after the childbirth.

In order to increase internal validity of the study, the participants were matched regarding confounders such as episiotomy (media-lateral), wound repairing method, type of thread, amount of anesthetic substance before incision and during wound repairing, birth attendant, and Apgar score at first and fifth minute. Furthermore, in order to minimize random error, two colleagues who were the same for educational level and job experience in labor recorded items of the REEDA checklist and control of perinea healing.

In order to blinding in the current research, drug and placebo was encoded by the pharmacist; so that the researcher and samples were not awared of the drug content. In addition, all the assessments were evaluated and recorded by the researcher and her colleague who were not aware of the type of drug.

Required instructions on way of caring of the sutures, adherence to personal hygiene, and washing the sutures with washing serum of normal saline, adherenece to sexual health, nutrition and physical activity level were provided by the researcher.

Two hours after labor, firstly one basic assessment was done on episiotomy wound and the directions of use of the medication was explained to each participant by the researccher. So that each partciapnt should use the 
ointment thoroughly and as $2 \mathrm{~cm}$ on the suture twice daily in 10 days after washing hands and drying the perinea region. According to the usual care of the postpartum ward, $500 \mathrm{mg}$ of cefalexin capsule every 6 to $7 \mathrm{~h}$ was prescribed to all the women after labor.

Each partcipant was asked to contact the researcher in case of any problem and complication including allergy, infection, itching, burning, stinging, dryness in the area of wound and ague to perform assessemnt and required attempts including urgent need on referral to clinic of postpartum care. All the partcipants were recommended to refer triage ward of the hospital at fifth and tenth day and after discharge, they were called prior to any visit to remind second and third visits.

\section{Statistical methods}

Primary data was assessed using Kolmogorov-Smirnov test to investigate normal distribution of quantitative data. Then, two independent -samples t- test, chi-square, repeated measure two factorial analysis of variance and Fischer's exact test were used. In order to analyze data, SPSS software version 23 was used and significant level was considered as less than 0.05 .

\section{Ethical considerations}

This study was approved in the Organizing Committee of Ethics in Medical Research at Shahid Beheshti University of Medical Sciences as the Committee of Ethics in Research of the Schools of Pharmacy, Nursing and Midwifery -Shahid Beheshti University of Medical Science on $15 / 4 / 2019$ by assigning the ethical code of IR.SBMU. PHARMACY.REC.1398.030 and was also registered in IRCT with the number: IRCT201811100411603N1 on $10 / 8 / 2019$.

Women eligible to participate in the study were enrolled voluntarily and with written consent at the beginning of the study and with a commitment not to impose costs on participants, having the right to dispense as well as confidentiality of information.

\section{Results}

Out of the 90 participants at the beginning of the study, 43 individuals were in the placebo group and 44 one in the $S$. marianum group. Three subjects ( 2 in the placebo group and 1 in the $S$. marianum group) were excluded (Fig. 1).

Data analysis showed no significant difference among two study groups on demographic and midwifery characteristics prior to the intervention $(P>0.05)$, scores obtained from health status forms in two groups were computed and compared in order to assess health status of the two groups, which two groups did not differ statistically significant $(P>0.05)$ (Table 1$)$.
In first $12 \mathrm{~h}$ after labor, two groups did not significantly differ regarding none of the REEDA variables $(P>0.05)$ (Table 3). However, the REEDA mean difference score in S. marianum ointment group in $12 \mathrm{~h}$ after childbirth, and either REEDA mean difference score or all its variables scores at fifth day and tenth day were statically significant comparing to control group which indicates decline in episiotomy wound healing $(P<0.001)$ (Tables 2 and 3$)$.

Figure 2 shows wound healing observed in two groups at different times.

Mean difference of pain severity in S. marianum ointment group in $12 \mathrm{~h}$ after labor, at fifth day and tenth day was statically significant comparing to control group which indicates decline in episiotomy pain severity $(P<0.001)$ (Table 2).

Figure 3 shows pain severity in two groups at different times.

Pain severity in S. marianum group comparing to placebo is estimated with confidence interval of $95 \%$ in Table 3 (Table 4).

No serious side effect for the drug was observed in the study except for itching and burning which was the same in two groups of $S$. marianum ointment and placebo ointment (one case of itching and dryness and two cases of topical burning in intervention group, and 4 cases of topical skin dryness in control group at fifth day of using). Thereby, it was recommended to use washing serum until compete relief of the problem and there was no more need to an additional treatment.

\section{Discussion}

In the current study, S. marianum ointment was effective in healing wound and decline in severity of episiotomy pain comparing to placebo ointment group.

Only one study has been done to investigate S. marianum orally on wound recovery on human samples to date [42], and this is the first time that the efficacy of topical form of this herb is thoroughly investigated in a controlled clinical trial on wound healing and pain decline in humans.

Results of a study which investigated the effect of $S$. marianum on wound healing in rats showed that topical use of S. marianum leads to wound recovery regarding lesser redness, exudates and swelling. The researchers found that $S$. marianum ointment is a promising therapeutic agent to treat wounds through antioxidant and anti-inflammatory property [40].

In the present study also at fifth and tenth day after labor, redness and edema in S. marianum group comparing to placebo group is significantly lower which shows lesser inflammation in S. marianum group.

The result of a study accomplished on skin wounds induced in mice by the Leishmania major showed that, 


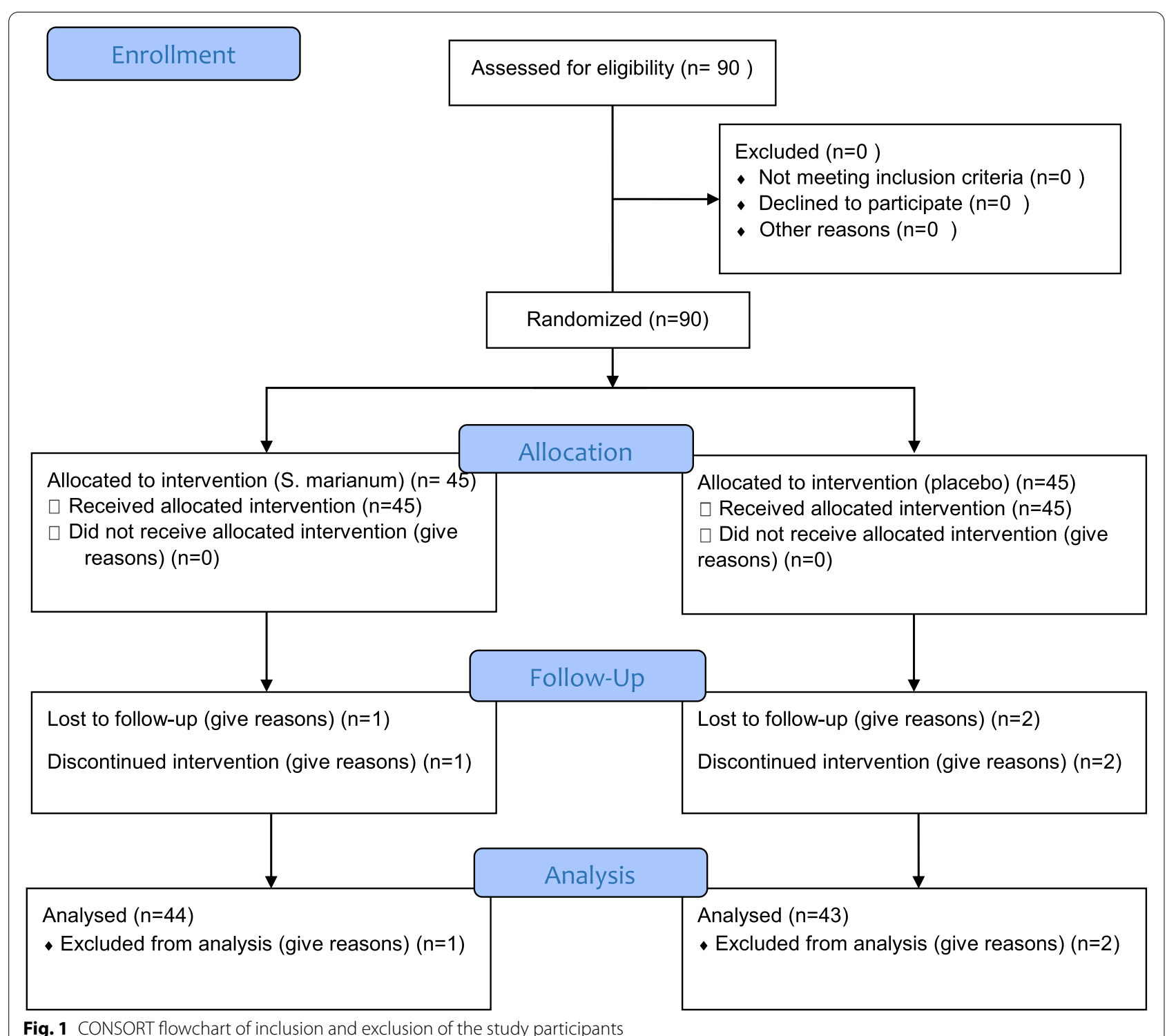

Fig. 1 CONSORT flowchart of inclusion and exclusion of the study participants

sylimarin gel in both concentration of 5 and $10 \%$ accelerate wound closure and also improve collagen synthesis and vascular regeneration through increase in length density, volume density and mean diameter of blood vessels [54].

In addition, the pain mean score in the intervention group showed significant statistical difference comparing to the control group. In an experimental study sedative effects of sylimarin which was used intra-peritoneally and its interaction with histamine H1 receptors in 42 wistar rats was assessed and analgesic effects of sylimarin was investigated using Formalin test by emphasizing histaminergic neurotransmitter system in wistar rats. The results showed that sylimarin has analgesic effects which probably are induced through histamine inhibition [56].

The study by Jadhav, G. B et al. conducted on mice showed that sylimarin herbal medicine has analgesic property which probably is induces through inhibition of prostaglandin synthesis [57]. Flavonoids (including silymarin) are good antioxidants [58], it seems that this compound implements its pain decreasing effects through inhibition of releasing harmful enzymes and histamins which causes allergy and swelling. In addition, flavonoids can control pain centrally through various mechanisms including affecting on gama amino butiric acid (GABA) receptors and inhibiting enzymes involved in brain [59]. The effect of flavonoids on pain reduction has been 
Table 1 Demographic characteristics of the 2 groups

\begin{tabular}{|c|c|c|c|}
\hline \multicolumn{4}{|l|}{ Treatment Categories } \\
\hline \multirow[t]{2}{*}{ Variable } & S. marianum ointment & Placebo & \multirow[t]{2}{*}{$p$-value } \\
\hline & Mean/SD & Mean/SD & \\
\hline Age (years) & $26.41 \pm 4.77$ & $18.24 \pm 5.38$ & ${ }^{*} P=0.14$ \\
\hline $\mathrm{BMI}(\mathrm{m} 2 \mathrm{Kg})$ & $25.31 \pm 1.89$ & $25.78 \pm 2.23$ & ${ }^{*} P=0.28$ \\
\hline Birth Weight (gram) & $3364.72 \pm 281.9$ & $3392.79 \pm 79$ & ${ }^{*} P=0.30$ \\
\hline Neonate Head circumference (cm) & $38.93 \pm 1.5$ & $34.27 \pm 1.68$ & ${ }^{*} P=0.28$ \\
\hline Duration of first stage of labor (minute) & $146.52 \pm 71.02$ & $125.23 \pm 1.57$ & ${ }^{*} P=0.14$ \\
\hline Duration of second stage of labor (minute) & $17.87 \pm 13.94$ & $21.51 \pm 19.43$ & ${ }^{*} P=0.54$ \\
\hline Duration of third stage of labor (minute) & $4.52 \pm 1.57$ & $5.32 \pm 2.42$ & ${ }^{*} P=0.80$ \\
\hline Time rupture of membranes (minute) & $168.95 \pm 120.12$ & $189.53 \pm 126.16$ & ${ }^{*} P=0.43$ \\
\hline Number of sutures on skin & $0.52 \pm 5.09$ & $0.69 \pm 5.18$ & ${ }^{*} P=0.52$ \\
\hline Number of analgesics used & $25.78 \pm 2.23$ & $38.93 \pm 1.50$ & ${ }^{*} P=0.10$ \\
\hline \multicolumn{4}{|l|}{ Treatment Categories } \\
\hline \multirow[t]{2}{*}{ Variable ointment } & S. marianum & Placebo & \multirow[t]{2}{*}{$p$-value } \\
\hline & Number (\%) & Number (\%) & \\
\hline \multicolumn{4}{|l|}{ Educational level (woman) } \\
\hline Elementary & $25(11)$ & $16.3(7)$ & \multirow{4}{*}{${ }^{* *} P=0.78$} \\
\hline Middle school & $22.7(10)$ & $27.9(12)$ & \\
\hline High school & $43.2(19)$ & $46.5(20)$ & \\
\hline University & $9.1(4)$ & $9.3(4)$ & \\
\hline \multicolumn{4}{|l|}{ Health status } \\
\hline absolutely desirable & $2(4.5)$ & $1(2.3)$ & \multirow{3}{*}{${ }^{* *} P=0.85$} \\
\hline Approximately desirable & $38(86.4)$ & $38(4.88)$ & \\
\hline Undesirable & $4(1.9)$ & $4(9.3)$ & \\
\hline
\end{tabular}

*Independent t-tests **Mann Whitney

Table 2 Comparison of mean scores of pain severity and wound healing based on assessment time in two groups

\begin{tabular}{|c|c|c|c|}
\hline \multicolumn{4}{|l|}{ Treatment Categories } \\
\hline Variable & $12 \mathrm{~h}$ after labor & Fifth day after labor & Tenth day after labor \\
\hline Pain severity group & Mean/SD & Mean/SD & Mean/SD \\
\hline S. marianum ointment & $6 \pm 2.03$ & $2.95 \pm 2.03$ & $0.11 \pm 0.53$ \\
\hline Placebo ointment & $7.39 \pm 2$ & $2.07 \pm 5.20$ & $7.39 \pm 2$ \\
\hline$p$-value & & ${ }^{*} P<0.001$ & \\
\hline \multicolumn{4}{|l|}{ Treatment Categories } \\
\hline \multirow{2}{*}{$\begin{array}{l}\text { Variable } \\
\text { Wound healing }\end{array}$} & $12 \mathrm{~h}$ after labor & Fifth day after labor & Tenth day after labor \\
\hline & Mean/SD & Mean/SD & Mean/SD \\
\hline S. marianum ointment & $0.38 \pm 0.75$ & $0.27 \pm 0.54$ & $0.22 \pm 0.52$ \\
\hline Placebo ointment & $1.02 \pm 1.18$ & $1.65 \pm 1.54$ & $1.81 \pm 1.82$ \\
\hline$p$-value & & ${ }^{*} P<0.001$ & \\
\hline
\end{tabular}

*Two way repeated measure Test for comparing two groups

confirmed in a similar study which aimed to examine the effect of combinatory ointment of chamomile and calendula on episiotomy pain severity [60].

This study despite attempts in minimzing probable errors had limitations, including lack of possibility of controlling factors such as indivdiual differences of samples regarding perinea tissue, nutritional status and physical movement in each indivdiual which was tried to control it by providing identical trainings and random allocations.

In addition, since perception of pain and expression of it is different in various individuals, it might 
Table 3 Comparison of REEDA Scale in two groups

\begin{tabular}{|c|c|c|c|c|}
\hline \multicolumn{5}{|l|}{ Treatment Categories } \\
\hline \multirow{2}{*}{$\begin{array}{l}\text { Variable labor } \\
\text { S. marianum ointment }\end{array}$} & Before intervention & $12 \mathrm{~h}$ after labor & Fifth day after & Tenth day after labor \\
\hline & Mean/SD & Mean/SD & Mean/SD & Mean/SD \\
\hline Redness & $0.25 \pm 0.57$ & $0.15 \pm 0.42$ & $0.04 \pm 0.21$ & $0.04 \pm 0.21$ \\
\hline Edema & $0.15 \pm 0.36$ & $0.09 \pm 0.29$ & $0.02 \pm 0.15$ & $0.02 \pm 0.15$ \\
\hline Ecchymosis & $0.13 \pm 0.40$ & $0.13 \pm 0.40$ & $0.04 \pm 0.21$ & 0 \\
\hline Discharge from the wound & 0 & 0 & 0 & $0.15 \pm 0.42$ \\
\hline Wound edge continuity & 0 & 0 & $0.15 \pm 0.36$ & 0 \\
\hline \multicolumn{5}{|l|}{ Treatment Categories } \\
\hline \multirow{2}{*}{$\begin{array}{l}\text { Variable } \\
\text { Placebo ointment }\end{array}$} & Before intervention & $12 \mathrm{~h}$ after labor & Fifth day after labor & Tenth day after labor \\
\hline & Mean/SD & Mean/SD & Mean/SD & Mean/SD \\
\hline Redness & $0.32 \pm 0.56$ & $0.32 \pm 0.56$ & $0.34 \pm 0.52$ & $0.30 \pm 0.51$ \\
\hline Edema & $0.29 \pm 0.46$ & $0.20 \pm 0.46$ & $0.20 \pm 0.46$ & $0.20 \pm 0.46$ \\
\hline Ecchymosis & $0.27 \pm 0.63$ & $0.34 \pm 0.65$ & $0.32 \pm 0.64$ & $0.16 \pm 0.43$ \\
\hline Discharge from the wound & 1 & $0.46 \pm 0.21$ & $0.11 \pm 0.32$ & $0.86 \pm 0.98$ \\
\hline Wound edge continuity & 1 & $0.46 \pm 0.21$ & $0.65 \pm 0.75$ & $0.27 \pm 0.59$ \\
\hline $\begin{array}{l}\text { Variable } \\
{ }^{*} P \text {-value }\end{array}$ & Before intervention & $12 \mathrm{~h}$ after labor & Fifth day after labor & Tenth day after labor \\
\hline Redness & $P=0.32$ & $P=0.25$ & $P=0.003$ & $P=0.003$ \\
\hline Edema & $P=0.59$ & $P=0.34$ & $P=0.04$ & $P=0.04$ \\
\hline Ecchymosis & $P=0.53$ & $P=0.19$ & $P=0.01$ & $P=0.04$ \\
\hline Discharge from the wound & 1 & $P=0.14$ & $P=0.03$ & $P=0.01$ \\
\hline Wound edge continuity & 1 & $P=0.14$ & $P=0.001$ & $P=0.001$ \\
\hline
\end{tabular}

* Mann Whitney

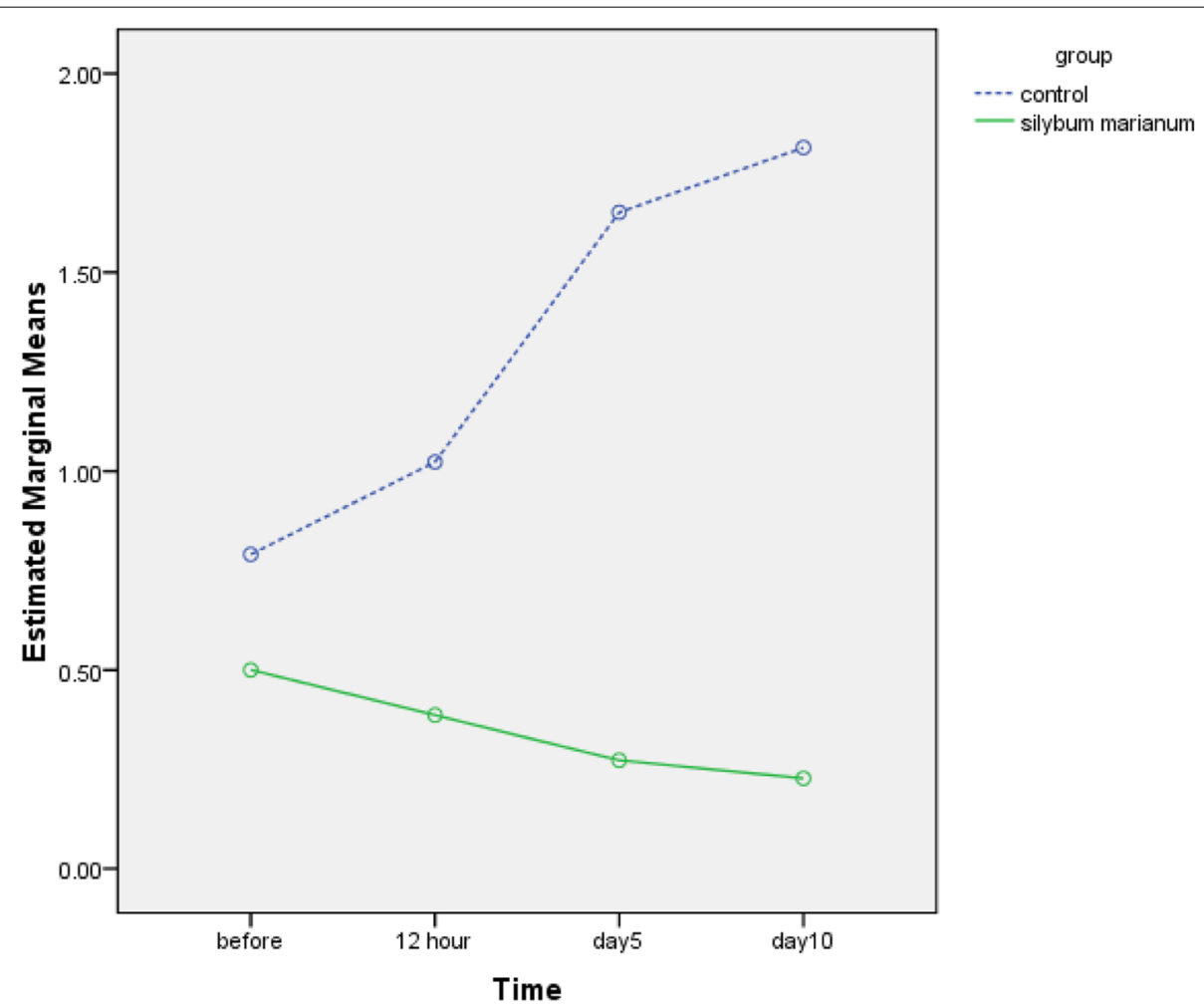

Fig. 2 Comparison of healing in two groups of S. marianum ointment and Placebo ointment in primiparous women 


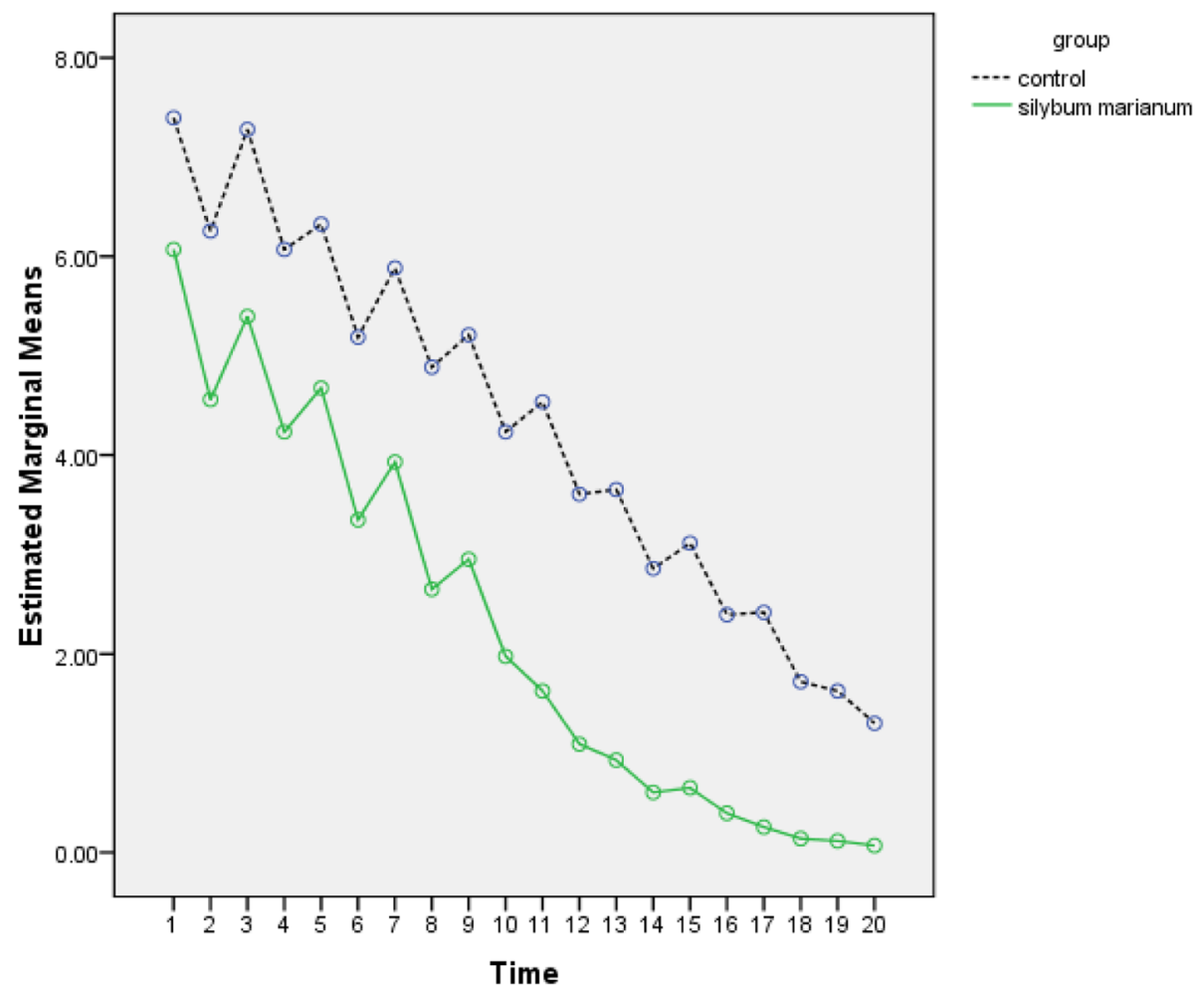

Fig 3 Comparison of pain severity in two groups of S. marianum ointment and Placebo ointment in primiparous women

Table 4 Pain severity in two groups of S. marianum ointment and Placebo ointment with confidence interval of 95\%

\begin{tabular}{llllll}
\hline Parameter & Estimate & STD.error & $p$-value & \multicolumn{2}{l}{$\begin{array}{l}95 \% \text { Confidence } \\
\text { Interval }\end{array}$} \\
\cline { 3 - 6 } & & & & $\begin{array}{l}\text { Lower } \\
\text { Bound }\end{array}$ & $\begin{array}{l}\text { Upper } \\
\text { bound }\end{array}$ \\
\hline group & -0.973 & 0.184 & .000 & -1.339 & -0.981 \\
\hline
\end{tabular}

approximately affect the results, however it was tried to decrease distribution of pain severity measurement among samples using a standard ruler of pain record, blinding and random allocation.

The strengths of the study were triple masking, controlling entry of confounding variables at the beginning of sampling, following up the individuals by phone, and assessment of wound healing by two independent researchers.

\section{Conclusion}

$S$. marianum is effective in accelerating wound healing process and decreasing episiotomy pain without inducing any complication and the participants experienced lesser pain and discomfort after labor. The current study can be an instruction on starting studies related to Silybum marianum in future specifically for wound healing.
Although, our clinical trial has been conducted on a small sample and highly selected primiparous populations, this does not mean that these findings are not generalizable to the general community of pregnant women with episiotomy, but rather that the beneficial effects of s.marianum should be assessed on individuals with the least main inclusion criteria like older mothers and who differ in terms of their baseline characteristics from participants recruited in this study. Moreover, it is recommended to conduct further studies regarding efficacy of various doses and probable side effects of S. marianum on wound healing.

\section{Abbreviations}

s.marianum: Silybum marianum; REEDA Scale: Redness(R), Edema (E), Ecchymosis (E), Discharge from the wound (D), Approximation of the perineal tissues; IRCT: Iranian Registry of Clinical Trials.

\section{Supplementary Information}

The online version contains supplementary material available at https://doi. org/10.1186/s12906-021-03413-z.

\section{Additional file}

Additional file 1. CONSORT 2010 checklist of information to include when reporting a randomised trial*. 


\section{Acknowledgements}

We appreciate cooperation of Deputy of research at school of nursing and midwifery of the Shahid Beheshti University of Medical Sciences and also health care providers of Shahid Nourani Hospital at Talesh (Guilan Province) and all the women participating in the study.

\section{Authors' contributions}

ET was the master student who was involved in all process of the project including writing the proposal, data collection, and data analysis and preparing the manuscript. SH was the supervisor of the project and contributed to writing the proposal, writing draft and final proof of the manuscript. FM was the Pharmacognosy advisor of the project contributed to prepare the medicine and consulting the study design. MN was the biostatistics advisor of the project and contributed to research design, data analysis and data interpretation. All the authors read and approved the final manuscript for submission.

\section{Authors' information}

1 - Student Research Committee, School of Nursing \& Midwifery, Shahid Beheshti University of Medical Sciences, Tehran, Iran. 2- Department of midwifery, Midwifery \& Reproductive Health Research Center, School of Nursing \& Midwifery, Shahid Beheshti University of Medical Sciences, Tehran, Iran 3- Department of Pharmacognosy, School of Pharmacy, Shahid Beheshti University of Medical Sciences, Tehran, Iran. 4- Obstetrician, Guilan University of medical science, Noorani hospital, Talesh, Iran. 5-Assistant professor department of Basic sciences, Faculty of Nursing and Midwifery, Shahid Beheshti University of Medical Sciences, Tehran, Iran.

\section{Funding}

The authors did not receive any fund from the third party or any organization for implementation of the present research.

\section{Availability of data and materials}

The datasets used and/or analyzed during the current study are available from the corresponding author on reasonable request.

\section{Declarations}

\section{Ethics approval and consent to participate}

This study was approved in Medical Ethics committee of Shahid Beheshti University of Medical Sciences in 15/4/2019. After confirmation, the ethical code of IR.SBMU.PHARMACY.REC.1398.030 was given to it. The authors confirm that informed written consent was obtained from all participants.

\section{Consent for publication}

Not applicable.

\section{Competing interests}

Authors declare that they have no conflict of interests.

\section{Author details}

'Student Research Committee, School of Nursing \& Midwifery, Shahid Beheshti University of Medical Sciences, Tehran, Iran. ${ }^{2}$ Department of Midwifery \& Reproductive Health, School of Nursing \& Midwifery, Shahid Beheshti University of Medical Sciences, Vali Asr Ave., Ayatollah Rafsanjani Cross Road, Niayesh Complex, Tehran 1985717443, Iran. ${ }^{3}$ Midwifery \& Reproductive Health Research Center, School of Nursing \& Midwifery, Shahid Beheshti University of Medical Sciences, Tehran, Iran. ${ }^{4}$ Department of Pharmacognosy, School of Pharmacy, Shahid Beheshti University of Medical Sciences, Vali Asr Ave., Ayatollah Rafsanjani Cross Road, Niayesh Complex, Tehran 1991953381, Iran. ${ }^{5}$ Guilan University of medical science, Shahid Noorani Hospital, Talesh, Guilan Province 4271937916, Iran. ${ }^{6}$ Department of Basic sciences, Faculty of Nursing and Midwifery, Shahid Beheshti University of Medical Sciences, Tehran, IR, Iran.

Received: 5 November 2020 Accepted: 17 September 2021 Published online: 07 October 2021

\section{References}

1. Cunningham FG. Williams obstetrics / editors, F. Gary Cunningham, Kenneth J. Leveno, Steven L. Bloom, Jodi S. Dashe, Barbara L. Hoffman, Brian M. Casey, Catherine Y. Spong. 25th ed: Medical; 2014.

2. Ismail KMK, Webb SS. Episiotomy and second-degree tear. Gynecologic and obstetric surgery. Wiley; 2016. p. 488-9.

3. Kartal B, Kızılırmak A, Calpbinici P, Demir G. Retrospective analysis of episiotomy prevalence. J Turkish German Gynecol Assoc. 2017;18(4):190-4.

4. Trinh AT, Nippita TA, Dien TN, Morris JM, Roberts CL. Perineal length among Vietnamese women. Taiwanese J Obstet Gynecol. 2017;56(5):613-7.

5. Ahmed HM, Abdollah WH, Al-Tawil NG. Prevalence and risk factors of episiotomy and perineal tear in the maternity teaching hospital of Erbil City, Iraq. Erbil J Nurs Midwifery. 2019;2(1):44-50.

6. Karaçam Z, Ekmen H, Calişır H, Seker S. Prevalence of episiotomy in primiparas, related conditions, and effects of episiotomy on suture materials used, perineal pain, wound healing 3 weeks postpartum, in Turkey: a prospective follow-up study. Iran J Nurs Midwifery Res. 2013;18(3):237-45.

7. Izuka E, Dim C, Chigbu C, Obiora-Izuka C. Prevalence and predictors of episiotomy among women at first birth in Enugu, south East Nigeria. Ann Med Health Sci Res. 2014;4(6):928-32.

8. Ghorbani Ranjbary VS, Zarei A, Asmarian SH, Jouibar F. Investigation of hydralcoholic extract of Silybum marianum on open wound healing in mice. J Babol Univ MED Scince. 2014;16(5):35-41.

9. Aradmehr M, Azhari S, Ahmadi S, Azmoude E. The effect of chamomile cream on episiotomy pain in Primiparous women: a randomized clinical trial. J Caring Sci. 2017;6(1):19-28.

10. East CE, Sherburn M, Nagle C, Said J, Forster D. Perineal pain following childbirth: prevalence, effects on postnatal recovery and analgesia usage. Midwifery. 2012;28(1):93-7.

11. Azhari S, Aradmehr M, Rakhshandeh H, Tara F, Shakeri MT. The effects of chamomile cream on wound healing of episiotomy in primiparous women. Iranian J Obstet Gynecol Infertility. 2014;17(93):16-26.

12. SchremI S, Szeimies RM, Prantl L, Landthaler M, Babilas P. Wound healing in the 21st century. J Am Acad Dermatol. 2010;63(5):866-81.

13. Chen X, Zhou X, Xia X, Chen Y, Mao T, Shi X, et al. Retrospective analysis of related factors affecting skin wound healing. Int J Clin Exp Med. 2018;11(8):8615-21.

14. Han G, Ceilley R. Chronic wound healing: a review of current management and treatments. Adv Ther. 2017;34(3):599-610.

15. Ghaderi R. Novel advancements in wound healing. J Birjand Univ Med Sci. 2014;21(1):1-19.

16. Lindley LE, Stojadinovic O, Pastar I, Tomic-Canic M. Biology and biomarkers for wound healing. Plast Reconstr Surg. 2016;138(3):18S.

17. Hampton S. The role of alginate dressings in wound healing. Diabet Foot. 2004;7(4):162-7.

18. Almeida SFS, Riesco MLG. Randomized controlled clinical trial on two perineal trauma suture techniques in normal delivery. Rev Latino-Am Enfermagem. 2008;16(2):272-9.

19. Andrews $V$, Thakar R, Sultan AH, Jones PW. Evaluation of postpartum perineal pain and dyspareunia-a prospective study. Eur J Obstet Gynecol Reprod Biol. 2008;137(2):152-6.

20. Abedian Z, Navabi Rigi SD, Dadgar S, Esmaili H. Comparing the effect of colling gel pads and ice pack, after episiotomy, on the intensity od perinal pain. Iranian J Obstet Gynecol Infertility. 2007;10(2):79-86.

21. Alvarenga MB, de Oliveira SM, Francisco AA, da Silva FM, Sousa M, Nobre MR. Effect of low-level laser therapy on pain and perineal healing after episiotomy: a triple-blind randomized controlled trial. Lasers Surg Med. 2017;49(2):181-8.

22. Mahmoodi F, Mobaraki A. Assessment of effects of kegel exercises on reduction of perineal pain after episiotomy in primiparous women. Iranian J Obstet Gynecol Infertility. 2014;17(95):18-25.

23. Marra C, Pozzi I, Ceppi L, Sicuri M, Veneziano F, Regalia AL. Wrist-ankle acupuncture as perineal pain relief after mediolateral episiotomy: a pilot study. J Altern Complement Med. 2011;17(3):239-41.

24. Attarha M, Vacillian C, Akbary Torkestany N, Heydary T, Bayateyan Y. Effect of perineal massage during second phase of labor on episiotomy and laceration rates among nulliparous women. Hayat. 2009;15(2):15-22.

25. Pitangui ACR, Araújo RC, Bezerra MJS, Ribeiro CO, Nakano AMS. Low and high-frequency TENS in post-episiotomy pain relief: a randomized, double-blind clinical trial. Braz J Phys Ther. 2014;18(1):72-8. 
26. Sayar H, Gergerlioglu N, Seringec N, Ozturk P, Bulbuloglu E, Karabay G. Comparison of efficacy of phenytoin with hypericin in second-degree burn wound healing: an experimental study in rats. Med Sci Monit Basic Res. 2014;20:36-46.

27. Yahya S, Ozgoli G, Mojab F, Alavi Majd H, Shojaee A, Mirhaghjou N The effect of Hypericum perforatum cream on perineal pain after episiotomy in primiparous women. Iranian J Obstet Gynecol Infertility. 2015;18(159):1-7.

28. Eghdampour F, Jahdie F, Kheyrkhah M, Taghizadeh M, Naghizadeh S, Haghani $\mathrm{H}$. The effect of Aloe vera ointment in wound healing of episiotomy among primiparous women. Iranian J Obstet Gynecol Infertility. 2013;15(35):25-31.

29. Golezar S. Ananas comosus effect on perineal pain and wound healing after episiotomy: a randomized double-blind placebo-controlled clinical trial. Iran Red Crescent Med J. 2016;18(3).

30. Golmakani N, Rabiei Motlagh E, Tara F, Assili J, Shakeri MT. The effects of turmeric (Curcuma longa $\mathrm{L}$ ) ointment on healing of episiotomy site in primiparous women. Iranian J Obstet Gynecol Infertility. 2008;11(4):29-39.

31. Jahdie F, Egdampour F, Naghizadeh S, Kheyrkhah M, Tagizade M. Effect of Aloe vera and Calendula persica ointment on pain intensity of episiotomy in primiparous women. Q Horizon Med Sci. 2013;19(1):23-8.

32. Afshar M, Sattari Fard $H$, Shadi M, Ghaderi R. Repairing effects of Iran flora on wound healing. J Birjand Univ Med Sci. 2015;22(1):1-18.

33. Zargari A. Medicinal Plants, vol. 3. Tehran: Institue of Printing and Publishin University of Tehran; 1996. p. 34-8.

34. Sallehi-Sourmaghi MH. Medicinal plants and phytotherapy, vol. 1. Tehran: Donyaye Taghzie Pub; 2006. p. 69-171.

35. Ghahreman A. Color flora of Iran, vol. 9: Research Institute of Forests and Rangelands; 1983. p. 1095

36. Tooiserkani F, Hormati A, Moradi H. A Glimpse of Silybum marianum from the Perspective of Iranian Traditional Medicine and Modern Studies. Qom Univ Med Sci J. 2019;13(1):78-86.

37. Hashem M, Jun KY, Lee E, Lim S, Choo HY, Kwon Y. A rapid and sensitive screening system for human type I collagen with the aim of discovering potent anti-aging or anti-fibrotic compounds. Mol Cells. 2008;26(6).

38. Tabandeh MR, Oryan A, Mohhammad-Alipour A, Tabatabaei-Naieni A. Silibinin regulates matrix metalloproteinase 3 (stromelysine1) gene expression, hexoseamines and collagen production during rat skin wound healing. Phytother Res. 2013;27(8):1149-53.

39. Sharifi R, Rastegar H, Kamalinejad M, Dehpour AR, Tavangar SM, Paknejad M, Natanzi MM, Ghannadian N, Akbari M, Pasalar P. Effect of topical application of silymarin (Silybum marianum) on excision wound healing in albino rats. Acta Medica Iranica. 2012:583-8.

40. Zhao J, Lahiri-Chatterjee M, Sharma Y, Agarwal R. Inhibitory effect of a flavonoid antioxidant silymarin on benzoyl peroxide-induced tumor promotion, oxidative stress and inflammatory responses in SENCAR mouse skin. Carcinogenesis. 2000;21(4):811-6.

41. Tabari S, Carpi S, Polini B, Nieri P, Esfahani M, Moghadamnia A, et al. Topical application of silymarin enhances cutaneous wound healing in rats. S Afr J Bot. 2019;124:494-8.

42. Mahmoodi-Nesheli M, Alizadeh S, Solhi H, Mohseni J, Mahmoodi-Nesheli M. Adjuvant effect of oral Silymarin on patients' wound healing process caused by thermal injuries. Caspian J Intern Med. 2018;9(4):341-6.

43. Giorgi VS, Peracoli MT, Peracoli JC, Witkin SS, Bannwart-Castro CF. Silibinin modulates the NF-kappab pathway and pro-inflammatory cytokine production by mononuclear cells from preeclamptic women. J Reprod Immunol. 2012;95(1-2):67-72.

44. Osuchowski M, Johnson V, He Q, Sharma R. Alterations in regional brain neurotransmitters by Silymarin, a natural antioxidant flavonoid mixture, in BALB/c mice. Pharm Biol. 2004;42(4-5):384-9.
45. Taleb S, Ozgoli G, Mojab F, Nsiri M, Ahvazi M. Effect of Verbascum thapsus cream on intensity of episiotomy pain in primiparous women. Iranian J Obstet Gynecol Infertility. 2016;19(7):9-17.

46. Shahrahmani $\mathrm{H}$, Kariman $\mathrm{N}$. The effect of green tea ointment on episiotomy pain and wound healing in primiparous women: a randomized, double-blind, placebo-controlled clinical trial. National Libr Med. 2018:32(3):522-30.

47. Mirzaee F, Jannesari S, Kariman N, Mojab F, Nasiri M. The effect of Myrtus communis cream on wound healing and severity of episiotomy pain: double-blind clinical trial. Iranian J Obst Gynecol Infertility. 2019;22(8):52-61.

48. Shahrahmani H, Kariman N, Jannesari S, Rafieian-Kopaei M, Mirzaei M, Shahrahmani N. The effect of Camellia sinensis ointment on perineal wound healing in primiparous women. J Babol Univ Med Sci. 2018;20(5):7-15.

49. Hill PD. Psychometric properties of the reeda. J Nurse-Midwifery. 1990;35(3):162-5.

50. Amani R, Kariman N, Mojab F, Alavi H, Majidi S. Comparison of the effects of cold compress with gel packs and topical olive oil on episiotomy wound healing. J Babol Univ Med Sci. 2015;17(11):7-12.

51. Sabzaligol M, Safari N, Baghcjeghi N, Latifi M, Koohestani H, Bekhradi R, et al. The effect of Aloe vera gel on prineal pain \& wound healing after episiotomy. Complement Med J. 2014;4(2):766-75.

52. Farrar JT, Troxel AB, Stott C, Duncombe P, Jensen MP. Validity, reliability, and clinical importance of change in a $0-10$ numeric rating scale measure of spasticity: a post hoc analysis of a randomized, double-blind, placebo-controlled trial. Clin Ther. 2008;30(5):974-85.

53. Corkill A, Lavender T, Walkinshaw SA, Alfirevic Z. Reducing postnatal pain from perineal tears by using lignocaine gel: a double-blind randomized trial. Birth. 2001;28(1):22-7.

54. Rastegarian M, Ghanbarinasab Z, Borazjani R, Hosseini M, Aminnia S, Ashkani-Esfahani S, Asgari Q, Sarkari B. In vivo assay of wound healing activities of Silymarin extract on cutaneous wounds caused by leishmania major. Shiraz E-Med J. 2019;20(3).

55. Asgharikhatooni A, Bani S, Hasanpoor S, Alizade SM, Javadzadeh Y. The effect of equisetum arvense (horse tail) ointment on wound healing and pain intensity after episiotomy: a randomized placebo-controlled trial. Iran Red Crescent Med J. 2015;17(3).

56. Gholizade Nikpey M, Mojtahedin A, Seyedsharifi R. Pain-relieving effects of Silymarin and its interaction with histamine $\mathrm{H} 1$ receptors in rats. J Fasa Univ Med Sci. 2017;7(2):265-74.

57. Jadhav GB, Upasani CD. Analgesic effect of silymarin in experimental induced pain in animal models. J Pharm Res. 2009;2(8):1276-8.

58. Campos R, Garrido A, Guerra R, Valenzuela A. Silybin dihemisuccinate protects against glutathione depletion and lipid peroxidation induced by acetaminophen on rat liver. Planta Med. 1989;55(05):417-9.

59. Riaz M, Zia-UI-Haq M, Jaafar HZ. Common mullein, pharmacological and chemical aspects. Rev Bras. 2013;23(6):948-59.

60. Sadeghi Aval Shahr H, Davami B, Amini L, Kashanian M. Investigating the effect of chamomile-marigold ointment onEpisiotomy pain in nulliparous women. Complement Med J. 2018;8(2):2254-64.

\section{Publisher's Note}

Springer Nature remains neutral with regard to jurisdictional claims in published maps and institutional affiliations. 